\title{
Influence of Photoperiod over Morphometric and Hematological Parameters of Juvenile Piracanjubas (Brycon orbygnianus)
}

\author{
Mônica Rodrigues Ferreira Machado ${ }^{1}$, Eliane Aparecida de Andrade $^{2}$, Estefânia de Souza Andrade ${ }^{2}$, Daniella \\ Aparecida de Jesus Paula ${ }^{2}$, Julia Alvarenga Oliveira ${ }^{2}$, Adriano Carvalho Costa ${ }^{3}$, Ana Paula Peconick ${ }^{2}$ and Luis \\ David Solis Murgas ${ }^{2}$ \\ 1. Department of Biological Science, Federal University of Goiás (UFG), Campus Cidade Universitária, CEP 75801-615, Jataí, \\ Goiás, Brazil
}

2. Department of Veterinary Medicine, Câmpus Universitário, Federal University of Lavras (UFLA), Lavras, Minas Gerais, CEP 37200-000, Brazil

3. Department of Animal Science, Federal Institute of Rio Verde (IFRV), Rio Verde, Goiás, CEP 75901-970, Brazil

\begin{abstract}
The aim of this study was to evaluate morphometric and hematological parameters of juveniles Piracanjubas treated with two distinct photoperiod. Twenty nine fish with $100 \mathrm{~g}$, in a factorial design were performed in $18 \mathrm{~h}$ light:6 h dark (18L:6D) and 6L:18D two different photoperiod, and morphometric and hematological parameters were evaluated at $45 \mathrm{~d}$ and $90 \mathrm{~d}$ after photoperiod treatment. Benzocaine $1 \%$ was used for euthanasia. Fish were weighed and measured, so as visceral fat, liver and gonads. Hematocrit, total count of white cells, lymphocytes and neutrophils were counted. Results showed that there was no significant relationship between bodyweight and standard length. Significant interaction $(P=0.00018)$ had been found between the fat index (FI) and gonado-somatic index (GSI) and the photoperiod and time. At $90 \mathrm{~d}$, the fish kept in 18L:6D had a lower rate of fat than the fish kept in 6L:18D $(P<0.05)$. The GSI was higher in the group 6L:18D compared with the 18L:6D $(P<0.005)$. There was no interaction between photoperiod and period of treatment for total leukocyte count, however with $90 \mathrm{~d}$, the total leukocyte count was decreased $(P<0.05)$. Moreover, decrease of the hematocrit from $58.1 \%$ to $46.9 \%$ and an increase of lymphocytes from $31.5 \%$ to 43.5\% had been found in fish kept in 18L:6D after $90 \mathrm{~d}(P<0.05)$. Fish kept in 6L:18D presented an increase in segmented neutrophils and lymphocytes $(P<0.05)$. It is concluded that photoperiod maintained at $6 \mathrm{~L}: 18 \mathrm{D}$ for Piracanjubas permits a greater gonadal development and an amount of immune cells over the photoperiod maintained in 18L: 6D.
\end{abstract}

Key words: Circadian rhythm, fish maturity, cellular immune response, photoperiod.

\section{Introduction}

Piracanjuba (Brycon orbignyanus) is a migratory fish, native from Uruguay and Parana basin in Southwestern Brazil. This specie is sensitive to environmental degradation and is quite explored in sport fishing [1]. Therefore, its natural population has declined, being necessary efforts to reproduce in captivity, as captive characteristics can be rapid growth, omnivorous and easy adaptation to artificial

Corresponding author: Mônica Rodrigues Ferreira Machado, professor, research field: fish physiology. feeding [2].

Sexual maturity of this specie is reached at the age of three years [3], however, the production of these fish presents a series of obstacles, being mainly the high rate of cannibalism and competition for space and food. This dispute determines a heterogeneous lot, because of the energy spent by the territorial dispute and high mortality rate $[4,5]$. Consequently, it is necessary to develop management systems that determine the increased survival rate and decrease of the age of first maturity, thereby increasing its precocity and prolificacy. 
Among the parameters that can be changed to stimulate reproduction, photoperiod has been cited in several species [6-8]. Circadian rhythms determine the alterations in the hypothalamic-pituitary-gonadal axis, leading to release of gonadotropin-releasing hormone (GnRH) [8]. The increase in photoperiod determines the synthesis of hormones, such as steroids, insulin and catecholamines, while its reduction causes an increase in the levels of growth hormone and melatonin [6].

However, the effect of light on induction of puberty in fish is still unknown. Metabolic signals and environmental cues contribute to the onset of gonadal development [9], and changes induced by puberty determine the decrease in the gene expression of several proteins by dopamine [10]. Dopamine is known as the inhibitory hypothalamic-pituitary-gonadal axis in fish. Furthermore, melatonin have the ability to inhibit the hypothalamic-pituitary-gonadal axis via dopaminergic receptors [7].

Hormonal changes caused by the action of photoperiod can interfere with the physiological processes of teleost fish, and hematological parameters can use as an indicator of these changes. The basic proteins present in granules of leukocytes have defense function against microorganisms, causing their death. When they are released after the rupture of these cells [11], they also present great source of glycogen [12].

In teleost fish, the variation in the number of defense cells may indicate changes in the environment and stress [13-15]. However, several factors may contribute to quantitative variations in fish blood elements. These include length, weight, nutritional state, seasonal cycle and age [16, 17], and the environment in which the animal is maintained [18, 19].

The aim of this study was to evaluate morphometric and hematological parameters in juveniles Piracanjubas held in two distinct light:dark (L:D) photoperiod.

\section{Materials and Methods}

\subsection{Animal Housing and Maintenance}

The fish were donated by Eletrobras Furnas, Minas Gerais, Brazil and came from the reproductive period of 2013-2014. Twenty nine Piracanjubas with average weight $100 \mathrm{~g}$ and average length $15 \mathrm{~cm}$ were selected. Initially, the fish were kept for $45 \mathrm{~d}$ in a recirculation system and a photoperiod $12 \mathrm{~h}$ light:12 h dark (12L:12D) for adaptation. Later, these juveniles were assigned in five $500 \mathrm{~L}$ tanks of polyethylene, with a density of seven fish per box, with constant aeration in closed recirculating system for $45 \mathrm{~d}$. The boxes were kept in vivarium of the Federal University of Lavras (UFLA), and photoperiod was controlled individually by timers with 200 lux lamps used [20]. The photoperiodic treatments were performed with two periods of 18L:6D and 6L:18D, and these were chosen to mimic the summer and winter when the day or night longer present, respectively.

A blackout cloth was placed on the edge of the lid. The management was carried out only when the light from both boxes was lit. The management consisted of feeding commercial feed containing 35\% crude protein, collecting food debris and siphoning the bottom twice a day in box.

The food and cleaning operations of the box were performed at the same time in the two photoperiodic treatments, and the interval between the feeds was 6 $\mathrm{h}$, at which time the boxes lights were lit. The water quality parameters were performed one time per week. The room light was kept off when there was no steering. Two collection periods were carried out to evaluate morphometric and hematological measurements at $45 \mathrm{~d}$ (12 fish, three of each box) and at $90 \mathrm{~d}$ (17 fish, seven from photoperiod 18L:6D and 10 from photoperiod 6L:18D). Fish anesthesia was performed using $1 \%$ benzocaine. All the experimental procedures were carried out following the standards of the Ethics Committee on Animal Use (CEUA-UFLA). 


\subsection{Morphometric Evaluation}

For blood collect, fish were sedated with $1 \%$ benzocaine, with $5 \mathrm{~mL}$ syringes with EDTA by puncture of venal caudal. After blood collection, fish were allocated at benzocaine solution until opercular movement stopped. Fish body weight, standard and total body length were measured [21]. Caelomatic cavity diameter in three different position, anterior $\left(\mathrm{M}_{1}\right)$, middle $\left(\mathrm{M}_{2}\right)$ and posterior $\left(\mathrm{M}_{3}\right)$, were measured using a digital pachimeter. Gonads, liver [21] and visceral fat were weighed for the calculation of gonado-somatic index (GSI), hepatic and visceral fat index.

\subsection{Blood Analysis}

Hematocrit evaluation was performed with a microhematocrit tube, centrifuged for $5 \mathrm{~min}$ at 10,000 rpm. Total erythrocyte, thromobocytes and leukocytes were performed using a dilution of $9.9 \mathrm{~mL}$ of Natt-Herrick's solution (Conroy, 1998) added with 0.1 mL of blood (1: 1000) which was homogenized for 3 min and using a Neubauer chamber [17].

For number of erythrocytes $/ \mathrm{mm}^{3}$, the number of erythrocytes in five quadrants of newbauer chamber was multiplied 1,000 (dilution factor). For total number of leukocytes, the number of leukocytes counted on newbauer's chamber was multiplied 1,000 (dilution factor). The same was done for number of thrombocytes.

For differential counting of leukocytes an optical microscope (Nikon E200) was used with 400 and 1000 -fold increases. The differential count is a percentage count that differentiates the different leukocytes present in each blood sample. Values were expressed as a percentage.

The design was completely randomized in the scheme of subdivided plots, with two replicates. In the plots, the effects of the photoperiod (6 h and $18 \mathrm{~h}$ light) were evaluated, and in the subplots, the time effects (45 d and $90 \mathrm{~d}$ ) were evaluated. The analysis of variance was performed to verify the effect of the photoperiod, the time and the interaction of two, and the interaction was deployed when necessary. For the analysis of the data, the program $\mathrm{R}$ was used.

\section{Results}

Body weight, total body length, standard length, liver weight and measures of caelomatic $\left(\mathrm{M}_{1}, \mathrm{M}_{2}\right.$ and $\mathrm{M}_{3}$ ) did not show significant difference when comparing the two photoperiod (Table 1) nor interaction of these variables over the time. For photoperiod 18L:6D, weight was $121.0 \mathrm{~g}$, total length $20.4 \mathrm{~cm}$, standard length $17.6 \mathrm{~cm}$, hepato-somatic index (HSI) 1.4, and caelomatic measure M1, M2 and M3 were 20.7, 19.9 and $15.9 \mathrm{~cm}$, respectively. For photoperiod 6L:18D, the same variables were $134.3 \mathrm{~g}$, 20.3, 18.0, 1.3, 20.7, 20.5 and $14.2 \mathrm{~cm}$, respectively. Variables did not show significant interaction, when an analysis was made comparing the influence separately of the photoperiod and the time of treatment.

However if the photoperiod effect is excluded and the averages are compared, it is possible to perceive the increase in the total and standard length of the Piracanjubas. The fish at $90 \mathrm{~d}$ were larger (Table 2). The weight of Piracanjubas at $45 \mathrm{~d}$ was $117.4 \mathrm{~g}$ and at $90 \mathrm{~d} 136.0 \mathrm{~g}$. Considering the evaluations at $45 \mathrm{~d}$ and $90 \mathrm{~d}$, it was observed that Piracanjubas grew, and significantly $(P<0.05)$ increased their total and standard length (18.8 cm at $45 \mathrm{~d}$ and $21.3 \mathrm{~cm}$ at $90 \mathrm{~d}$ ), independent of the photoperiod. Standard length showed the same pattern, $15.3 \mathrm{~cm}$ at $45 \mathrm{~d}$ and $19.4 \mathrm{~cm}$ at $90 \mathrm{~d}(P<0.05)$. However, HSI $(1.8$ at $45 \mathrm{~d}$ and 1.1 at $90 \mathrm{~d}$ ) and caelomatic measurements $\mathrm{M}_{1}, \mathrm{M}_{2}$ and $\mathrm{M}_{3}$ showed no statistically significant difference for photoperiodic treatment or time of treatment (Tables 1 and 2).

An interaction between photoperiod and days of treatment was observed for visceral fat index and GSI (Figs. 1 and 2). From Fig. 1, it is possibly observed that at $45 \mathrm{~d}$, GSI was 0.12 for photoperiodic treatment 18L:6D and 0.14 for 6L:18D, being similar. However 
Table 1 Evaluation of morphometric parameters of Piracanjubas in different photoperiods.

\begin{tabular}{lll}
\hline \multirow{2}{*}{ Variables } & \multicolumn{2}{c}{ Photoperiod (light:dark) } \\
\cline { 2 - 3 } & 18L:6D & $6 \mathrm{~L}: 18 \mathrm{D}$ \\
\hline Weight $(\mathrm{g})$ & 121.0 & 134.3 \\
Total length $(\mathrm{cm})$ & 20.4 & 20.3 \\
Standard length $(\mathrm{cm})$ & 17.6 & 18.0 \\
Hepato-somatic index $(\mathrm{HSI})$ & 1.4 & 1.3 \\
Caelomatic measure 1 $\left(\mathrm{M}_{1} ; \mathrm{cm}\right)$ & 20.7 & 20.7 \\
Caelomatic measure 2 $\left(\mathrm{M}_{2} ; \mathrm{cm}\right)$ & 19.9 & 20.5 \\
Caelomatic measure 3 $\left(\mathrm{M}_{3} ; \mathrm{cm}\right)$ & 15.9 & 14.2 \\
\hline
\end{tabular}

Table 2 Evaluation of morphometric parameters of Piracanjubas after different treatment days, independent of the photoperiod.

\begin{tabular}{lll}
\hline \multirow{2}{*}{ Variables } & \multicolumn{2}{c}{ Time of treatment } \\
\cline { 2 - 3 } & $45 \mathrm{~d}$ & $90 \mathrm{~d}$ \\
\hline Weight $(\mathrm{g})$ & 117.4 & 136.0 \\
Total length $(\mathrm{cm})$ & $18.8^{\mathrm{a}}$ & $21.3^{\mathrm{b}}$ \\
Standard length $(\mathrm{cm})$ & $15.3^{\mathrm{a}}$ & $19.4^{\mathrm{b}}$ \\
Hepato-somatic index $(\mathrm{HSI})$ & 1.8 & 1.1 \\
Caelomatic measure 1 $\left(\mathrm{M}_{1} ; \mathrm{cm}\right)$ & 20.7 & 20.7 \\
Caelomatic measure 2 $\left(\mathrm{M}_{2} ; \mathrm{cm}\right)$ & 19.3 & 20.8 \\
Caelomatic measure 3 $\left(\mathrm{M}_{3} ; \mathrm{cm}\right)$ & 13.6 & 15.7 \\
\hline
\end{tabular}

Different letters in columns indicate statistical difference $(P<0.05)$.

at $90 \mathrm{~d}$, the GSI for the photoperiod 18L:6D was 0.25 and for photoperiod 6L:18D was $0.71(P<0.05)$. So GSI was higher for juveniles Piracanjubas maintained in photoperiodic treatment 6L:18D during $90 \mathrm{~d}$.

In Fig. 2, it is possible to observe the fat index in fish kept at 18L:6D presented a decrease tendency (2.78 at $45 \mathrm{~d}$ and 1.86 at $90 \mathrm{~d}$ ), although no significant difference $(P>0.05)$ was identified. While juvenile Piracanjubas kept in 6L:18D showed a fat index 2.01 at $45 \mathrm{~d}$ and 2.95 at $90 \mathrm{~d}$, showing significant increase in fat index. Among the hematological variables, there was a significant interaction $(P<0.05)$ between photoperiodic treatment and days of treatment for hematocrit, percentage of segmented neutrophils and lymphocytes (Table 3). Hematocrit was higher for Piracanjuba maintained at 18L:6D. Fish kept at 18L:6D photoperiod presented a decreased hematocrit from $58.1 \%$ at $45 \mathrm{~d}$ to $46.9 \%$ at $90 \mathrm{~d}$, however it was not significant. Fish kept at 6L:18D presented 43.8\% of hematocrit at $45 \mathrm{~d}$ and $42.7 \%$ at $90 \mathrm{~d}$, and those results are not significant. However, the hematocrit of fish kept on photoperiod 18L:6D was higher than of those maintained at 6L:18D $(P<0.05)$ (Table 3).

For total leukocytes, total thrombocytes, basophils, eosinophils, rods neutrophils, monocytes and leukocite granulocyte-PAS positive (LG-PAS), there was no interaction between photoperiod and day of treatments (Tables 4 and 5).

When comparing segmented neutrophils in different photoperiod, it is possible to observe that for fish kept at 18L:6D during $45 \mathrm{~d}$ was $58.1 \%$ and for fish kept under 6L:18D was $50.1 \%$ at the same period. For fish kept at $6 \mathrm{~L}: 18 \mathrm{D}$, hematocrit was of $43.8 \%$ at $45 \mathrm{~d}$ and $42.7 \%$ at $90 \mathrm{~d}$, showing a higher number for the last one $(P<0.05)$. Segmented neutrophils were higher for Piracanjuba kept at 6L:18D when compared with fish kept at 18L:6D at 90 d. For fish kept at 18L:6D, linfocytes were $31.5 \%$ at $45 \mathrm{~d}$ and $43.5 \%$ at $90 \mathrm{~d}$.

Piracanjubas kept at 6L:18D photoperiod, linfocytes were $40.5 \%$ at $45 \mathrm{~d}$ and $81.5 \%$ at $90 \mathrm{~d}$. Fish kept at 6L:18D presented a higher percentage of linfocytes than those kept at 18L:6D at $90 \mathrm{~d}$.

When evaluating the effect of days treatment, a numbers of total leukocyte was observed in fish kept for 
$90 \mathrm{~d}$ (Table 5). However, this effect was not observed when comparing the different photoperiods (Table 4). Thrombocytopenia was observed in fish kept at 18L:6D. It was also observed that fish at $90 \mathrm{~d}$ presented a lower amount of thrombocytes/mL (Table
5). Lower levels of basophyls were observed in fish kept at 6L:18D (Table 4), so as in fish kept for $90 \mathrm{~d}$ (Table 5). Significant differences were not found for eosinophils, monocytes, rod neutrophils and LG-PAS (Tables 4 and 5).

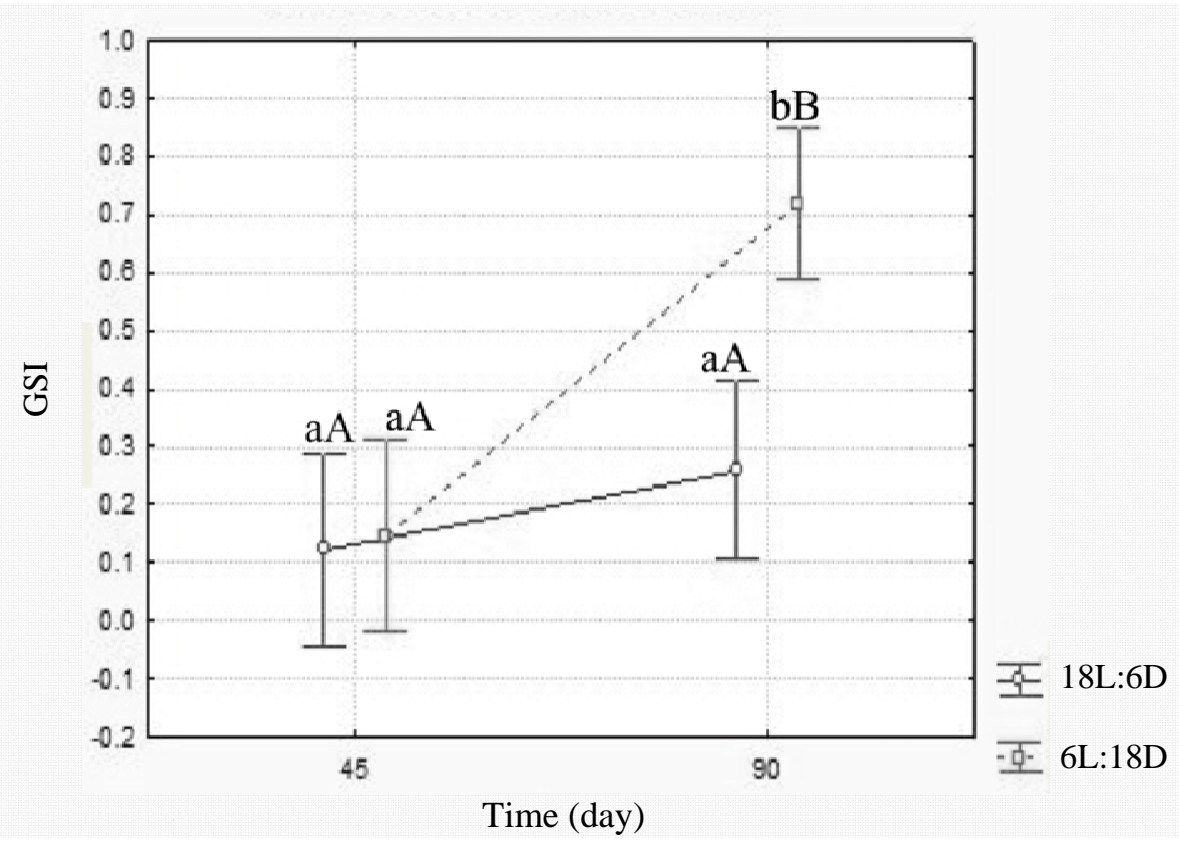

Fig. 1 Evaluation of gonado-somatic index (GSI) and the interaction between time and photoperiod.

Lowercase letters indicate differences between days of treatment and uppercases indicate difference between the photoperiodic treatment $(P<0.05 ; P=0.0018)$.

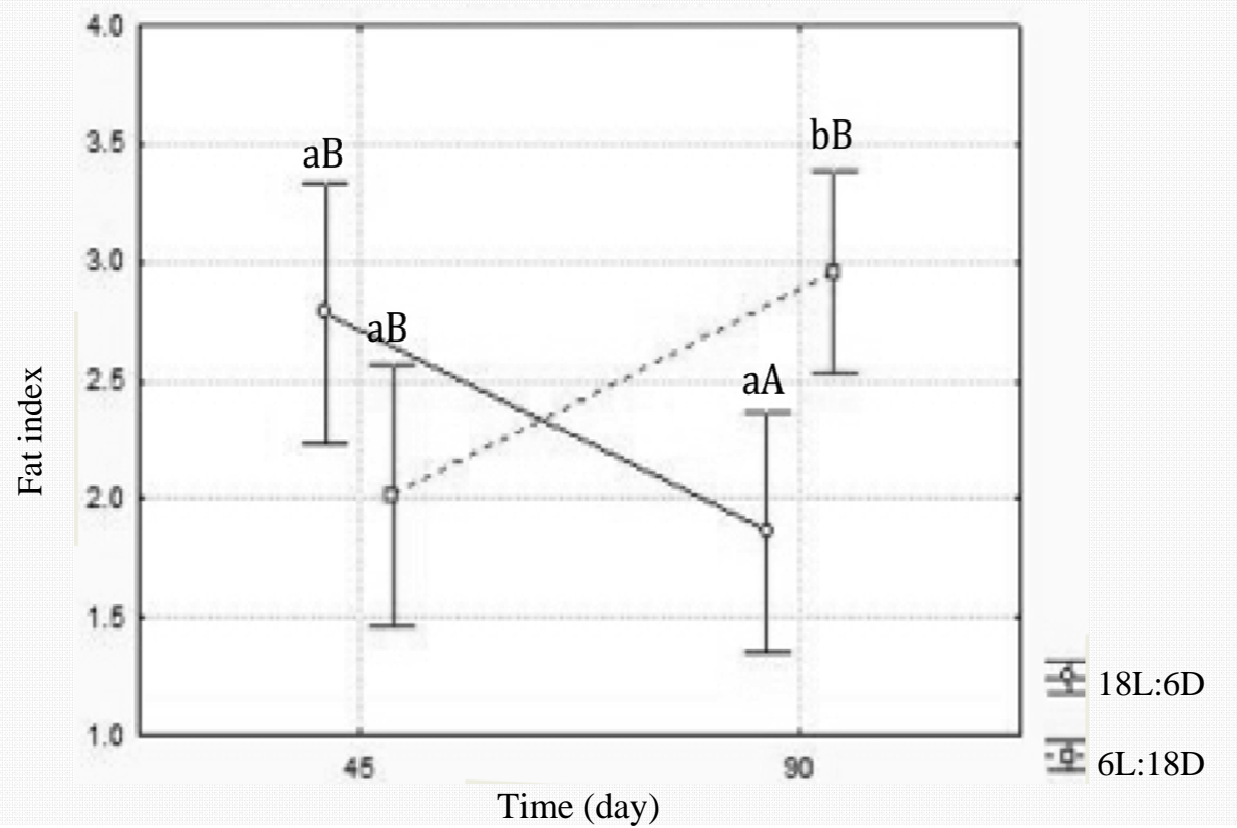

Fig. 2 Evaluation of fat index and the interaction between time and photoperiod.

Lowercase letters indicate difference between treatment days and uppercase letters indicate difference between photoperiods used. ( $P$ $<0.05 ; P=0.0018)$. 
Table 3 Variables that showed interaction between days of treatment and the photoperiod.

\begin{tabular}{llll}
\hline \multirow{2}{*}{ Variables } & Photoperiod (light:dark) & \multicolumn{2}{c}{ Days } \\
\cline { 3 - 4 } & & 45 & 90 \\
\hline \multirow{2}{*}{ Hematocrit (HT) (\%) } & 18L:6D & $58.1^{\mathrm{aA}}$ & $46.9^{\mathrm{aB}}$ \\
& 6L:18D & $43.8^{\mathrm{aA}}$ & $42.7^{\mathrm{aA}}$ \\
Segmented neutrophils (\%) & 18L:6D & $58.1^{\mathrm{aA}}$ & $48.0^{\mathrm{aA}}$ \\
& 6L:18D & $50.1^{\mathrm{aA}}$ & $69.7^{\mathrm{bB}}$ \\
Linfocytes (\%) & 18L:6D & $31.5^{\mathrm{aA}}$ & $43.5^{\mathrm{aA}}$ \\
\hline
\end{tabular}

Lowercase letters indicate differences between photoperiodic treatments at lines (18L:6D and 6L:18D); uppercase letters indicate differences between days of treatment at rows (45 d and $90 \mathrm{~d})(P<0.05)$.

Table 4 Values averages of the variables, when comparing the photoperiods.

\begin{tabular}{lll}
\hline \multirow{2}{*}{ Variables } & \multicolumn{2}{c}{ Photoperiod (light:dark) } \\
\cline { 2 - 3 } & $18 \mathrm{~L}: 6 \mathrm{D}$ & $6 \mathrm{~L}: 18 \mathrm{D}$ \\
\hline Total leukocytes/mL & $7.6 \times 10^{4}$ & $7.3 \times 10^{4}$ \\
Total trombocytes/mL & $9.0 \times 10^{6 \mathrm{a}}$ & $11.4 \times 10^{6 \mathrm{~b}}$ \\
Basophyls/mL & $0.8^{\mathrm{a}}$ & $0.2^{\mathrm{b}}$ \\
Eosinophyls/mL & 2.3 & 0.6 \\
Rodsneutrophils/mL & 4.8 & 5.9 \\
Monocytes/mL & 2.5 & 3.7 \\
LG-PAS/mL & 0.3 & 0.5 \\
\hline
\end{tabular}

Lowercase letters indicate differences between treatments $(P<0.05)$.

Table 5 Evaluation of hematological parameters in Piracanjubas kept in a recirculation system for $90 \mathrm{~d}$.

\begin{tabular}{lll}
\hline \multirow{2}{*}{ Variables } & \multicolumn{2}{c}{ Time oftreatments (days) } \\
\cline { 2 - 3 } & 45 & 90 \\
\hline Total leukocytes $/ \mathrm{mL}$ & $9.50 \times 10^{4 \mathrm{a}}$ & $4.50 \times 10^{4 \mathrm{~b}}$ \\
Total trombocytes/mL & $1.64 \times 10^{7 \mathrm{a}}$ & $1.67 \times 10^{6 \mathrm{~b}}$ \\
Basophyls/mL & $0.91^{\mathrm{a}}$ & $0.23^{\mathrm{b}}$ \\
Eosinophyls/mL & 0.16 & 0.11 \\
Rodneutrophils/mL & $6.66^{\mathrm{a}}$ & $3.83^{\mathrm{b}}$ \\
Monocytes $/ \mathrm{mL}$ & 4.10 & 2.40 \\
LG-PAS/mL & 0.75 & 0.20 \\
\hline
\end{tabular}

Different letters indicate statistical difference $(P<0.05)$.

\section{Discussion}

Handling used in intensive fish farms during the process of production or capture can promote increase or decrease of well-being, directly influencing the productive and reproductive parameters. Management is important, because it allows the maximum expression of genetic potential [22].

Changes in coelomatic measurements $\mathrm{M}_{1}, \mathrm{M}_{2}$ and $\mathrm{M}_{3}$ were not observed. The results indicate that fish were not able for reproduction, since they were juvenile. Bulging of coelomatic cavity would be an indicator of reproduction [22]. Accumulated visceral fat is related to excess of energy. In Piracanjubas maintained in 6L:18D, there was a greater accumulation of visceral fat, indicating storage of energy reserves, necessary for growth, periods of lack of food or winter anorexia [23]. Fig. 2 shows an increasing of total and standard length, which was influenced by the period of treatment but not by photoperiod, as opposed to fat index. Literatures indicate that Piracanjubas juveniles have the ability to store lipids, but are not adept at using this source to increase growth rates [2].

Consequently, the accumulation of visceral fat may 
be related to the gonadal increase, which would indicate a better preparation of the juveniles for the reproductive event in the pubertal age. Although it has been identified that the visceral fat does not have the capacity to synthesize, it is related to gonadal development, since there is a correlation between somatic growth, environmental factors and onset of puberty, which may affect gonadal maturation and fish growth [24].

However, GSI was influenced by the photoperiod. Fish kept in 6L:18D had a higher GSI than those maintained in 18L:6D at $90 \mathrm{~d}$. Melatonin is a hormone sintetized by pineal gland and produced during the night. This hormone is known as inhibitor of some fish reproduction, due to inhibition of GnRH from hipotalamus and diminish of oestradiol concentrations in brain. Both hormones are implicated in the induce of the onset of gonadal maturation [25]. However, the results in present study demonstrate that fish kept at lower photoperiod (6L:18D) presented higher GSI.

It is possible that the increase in fish activity caused by the increase of the photoperiod promoted an inhibition of gonadal growth, due to the energetic deviation necessary for homeostasis correction [26], overlapping the light stimulating mechanism on the gonadal pituitary hypothalamic axis, thus reducing the weight of the gonad in the Piracanjubas maintained in longer photoperiods.

The hematocrit of fish kept at 18L:6D for $45 \mathrm{~d}$ was higher than that of fish kept at 6L:18D $(P<0.05)$. This blood parameter is related to activity levels in teleost fish and increased demand for oxygen [27]. During the daytime period, there is an increase in the concentration of hormones, such as corticosteroids and catecholamines [6], and it is probable that fish kept in 18L:6D photoperiod showed higher amounts of those hormones, influencing their movement and consequently the hematocrit.

In the present work, the different photoperiods may have functioned as activators of the immune response, via damage associates molecular patterns (DAMPs).
This type of response act as sensors, inducers or mediators of sterile inflammatory stress responses through receptor recognition of the immune system [28, 29]. A leukopenia was observed in the fish kept during $90 \mathrm{~d}$. In fish, there are still few studies of the influence of activation by DAMPs and the immunological consequences [30-33]. Vera-Jimenez and Nielsen [34] describe different patterns of leukocyte response in fish after stimulation by pathogen-associated molecular pattern molecules (PAMPs) and DAMPs. Lima et al. [35] report that recirculation systems for intensive production determine a decrease in the immune defense capacity of fish, which can be indicated by the decrease of total leukocytes and total thrombocytes.

The fish kept for $90 \mathrm{~d}$ presented low number of basophyis and a decrease in the number of rods neutrophils, indicating that long periods of maintenance in recirculation systems make the mechanisms of compensatory response dysfunctional [26], and these compensatory responses are related to the altered metabolism and the number of cells in the immune system [36].

In fish, stress often causes leukopenia characterized by lymphopenia and neutrophilia [37]. The influence of photoperiod was observed on lymphocytes and segmented neutrophils separately, but not in relation to total leukocytes. Fish kept in 6L:18D photoperiod for $90 \mathrm{~d}$ presented higher amounts of segmented neutrophils and lymphocytes than fish kept at this time in 18L:6D. Falcon et al. [38] comment that stress severity may reduce the total number of circulating cells related to organic defense, corroborating the results found.

The total leukopenia associated with lymphopenia induced in Piracanjubas kept at photoperiodic treatment 18L:6D may be indicative of stress, which promotes a decrease in the number of circulating cells related to organic defense. Leukopenia may be secondary to recruitment of cells, mainly neutrophils representing $60 \%$ of white blood cells to tissues due to 
activation of the innate immune response by DAMPs. It is possible that the association between the photoperiod and the maintenance of these fish may increase the challenge, promoting a cumulative effect on the response to stress. In addition, thrombocytes showed a decrease in numbers in fish kept in larger photoperiod, which could be caused by stress, since they also have a defense function [39].

\section{Conclusions}

Thus, it is possible to affirm that the increase of the photoperiod determines a decrease of visceral fat and GSI, but does not influence the somatic growth of these animals. In addition, the increase in photoperiod promoted an increase in hematocrit, but also a reduction of total leukocytes and total thrombocytes, with a reduction of segmented neutrophils and lymphocytes. Therefore, the photoperiod increase is indicated to promote puberty induction, and the excess light promote a stress and energy deviation to maintain the homeostasis. However, it is not indicated for juvenile Piracanjubas in recirculation systems, since the reduction of gonadal tissue and adipose tissue in the future may negatively influence the selection of these fish for possible reproduction. The immunomodulation caused by the photoperiod should be studied in more detail and in future works to the conclusion that although a leucopenia occurs with the excess of light, it can be transitory and with the final protective effect.

\section{Acknowledgments}

The authors show their appreciation to National Research Consil (CnPQ), Comission of Advanced Superior level (CAPES), Foundation of Research of Minas Gerais (FAPEMIG), Brazilian Electric Centrals (Eletrobrás/FURNAS) for postdoctoral fellowship, resources for project realization and donation of fish.

\section{References}

[1] Conte, L., Bozano, G. L. N., and Ferraz De Lima, J. A. 1995. "Influence of Feeding System on Growth of
Piracanjuba Brycon orbignyanus in Cages.” Boletim Técnico CEPTA 8: 49-59. (in Portuguese)

[2] Borba, M. R., Fracalossi, D. M., Pezzato, L. E., Menoyo, D., and Bautista, J. M. 2003. "Growth, Lipogenesis and Body Composition of Piracanjuba (Brycon orbignyanus) Fingerlings Fed Different Dietary Protein and Lipid Concentrations.” Aquatic Living Resources 16 (4): 362-9. (in Portuguese)

[3] Ceccarelli, P. S., and Senhorini, J. A. 1996. "Brycon: Enabling the Production of Fingerlings.” Panorama da Aqüicultura 35 (6): 10-1. (in Portuguese)

[4] Gomes, L. C. 1998. "Semi-intensive Breeding System for Larvae of Brycon cephalus." Revista Panorama da Aqüicultura 45 (8): 15-21. (in Portuguese)

[5] Gomes, L. C., Baldisserotto, B., and Senhorini, J. A. "Effect of Stocking Density on Water Quality, Survival and Growth of Larvae of the Matrinxã, Brycon cephalus (Characidae), in Ponds.” Aquaculture 183 (1-2): 73-81.

[6] Maywood, E. S., O’Neill, J. S., Chesham, J. E., and Hastings, M. H. 2007. "Minireview: The Circadian Clockwork of the Suprachiasmatic Nuclei-Analysis of a Cellular Oscillator That Drives Endocrine Rhythms.” Endocrinology 148 (12): 5624-34.

[7] Chang, J. P., Sawisky, G. R., Mitchell, G., Uretsky, A. D., Kwong, P., Grey, C. L., Meints, A. N., and Booth, M. 2010. "PACAP Stimulation of Maturational Gonadotropin Secretion in Goldfish Involves Extracellular Signal-Regulated Kinase, but Not Nitric Oxide or Guanylate Cyclase, Signaling.” Gen. Comp. Endocrinol. 165 (1): 127-35.

[8] Yaron, Z. 1995. "Endocrine Control of Gametogenesis and Spawning Induction in the Carp.” Aquaculture 129: 49-73.

[9] Nocillado, J. N., and Elizur, A. 2008. "Neuroendocrine Regulation of Puberty in Fish: Insights from the Grey Mullet (Mugil cephalus) Model.” Mol. Reprod. Dev. 75 (2): 355-61.

[10] Dufour, S., Huang, Y. S., Rousseau, K., Sbaihi, M., Le Belle, N., Vidal, B., Marchelidon, J., Quérat, B., Burzawa-Gérard, E., Chang, C. F., and Schmitz, M. 2000. "Puberty in Teleosts: New Insights into the Role of Peripheral Signals in the Stimulation of Pituitary Gonadotropins.” In Proceedings of the 6th International Symposium on the Reproductive Physiology of Fish, 455-61.

[11] Araújo, C. S. O., Tavares-Dias, M., Gomes, A. L. S., Andrade, S. M. S., Lemos, J. R. G., Oliveira, A. T., and Cruz, W. R. 2009. Parasitic Infections and Blood Parameters in Arapaima gigas (Schinz, 1822) (Arapaimidae) Grown in the State of Amazonas, Brazil. Vol. 1. Macapá: Embrapa Amapá, 389-424. (in Portuguese) 
[12] Veiga, M. L., Egam, M. I., Ranzani-Paiva, M. J. T., and Rodrigues, E. L. 2000. "Morphological and Cytochemical Aspects of the Blood Cells of Salminus maxillosus (Valenciennes, 1840) (Characiformes: Characidae).” Revista Chilena de Anatomia 18 (2): 245-50. (in Spanish)

[13] Gill, T. S., and Pant, J. C. 1985. "Mercury-Induced Blood Anomalies in the Freshwater Teleost Barbus conchonius Ham..” Water, Air and Soil Pollution 24 (2): 165-71.

[14] Santos, M. A., and Hall, A. 1990. "Influence of Inorganic Lead on the Biochemical Blood Composition of the Eel, Anguilla anguilla L..” Ecotoxicology and Environmental Safety 20 (1): 7-9.

[15] Mahajan, C. L., and Dheer, J. S. 1979. "Cell Types in the Peripheral Blood of an Air-Breathing Fish Channel punctatus.” Journal of Fish Biology 14 (5): 481-7.

[16] Larsson, A., Johansson-Sjobeck, M. J., and Fange, R. 1976. "Comparative Study of Some Haematological and Biochemical Blood Parameters in Fishes from Shagerrak." Journal of Fish Biology 9 (5): 425-40.

[17] Ranzani-Paiva, M. J. T. 1991. "Hematology in Fish.” In Histology in Fish, edited by Santos, H. S. L. São Paulo: FCAV-UNESP, 65-70. (in Portuguese)

[18] Hickey, C. R. 1982. "Comparative Hematology of Wild and Captive Cunners.” Trans. American Fish. Soc. 111 (2): 242-9.

[19] Tavares-Dias, M., Sandrim, E. F. S., and Sadrim, A. E. 1998. "Hematological Characteristics of Tambaqui Colossoma macropomum (Cuvier, 1818) (Osteichthyes: Characidae) in an Intensive Monoculture System: Part I, Red Cell.” Revista Brasileira de Biologia 58 (2): 197-202. (in Portuguese)

[20] Felizardo, V. O., Murgas, L. D., Andrade, E. S., López, P. A., Freitas, R. T., and Ferreira, M. R. 2012. "Effect of Timing of Hormonal Induction on Reproductive Activity in Lambari (Astyanax bimaculatus).” Theriogenology 77 (8): 1570-4.

[21] Ellis, S. C., and Reigh, R. C. 1991. "Effect of Dietary Lipid and Carbohydrate Levels on Growth and Body Composition of Juvenile Red Drum, Sciaenops ocellatus." Aquaculture 97 (4): 383-94.

[22] Woynarovich, E., and Horváth, L. 1983. The Artificial Propagation of Tropical Fish. Brasília: FAO/CODEVASF/CNPq, 220. (in Portuguese)

[23] Wicker, A. M., and Johnson, W. E. 1987. "Relationships among Fat Content, Condition Factor and First Year Survival of Florida Largemouth Bass.” Trans. American Fish. Soc. 116 (2): 264-71.

[24] Gur, G., Melamed, P., Gissis, A., and Yaron, Z. 2000. "Changes along the Pituitary-Gonadal Axis during Maturation of the Black Carp, Mylopharyngodon piceus.” J. Exp. Zool. 286 (4): 405-13.

[25] Dufour, S., Weltzien, F. A., Sebert, M. E., Le Belle, N.,
Vidal, B., Vernier, P., and Pasqualini, C. 2005. "Dopaminergic Inhibition of Reproduction in Teleost Fishes: Ecophysiological and Evolutionary Implications.” Ann. New York Acad. Sci. 1040: 9-21.

[26] Santos, L. R. B., and Oba, E. T. 2009. "Diet: An Important Tool for Handling Fish in the Crop." In Management and Health of Fish in Cultivation, edited by Tavares-Dias, M. Macapá: Embrapa Amapá. (in Portuguese)

[27] Lay, P. A., and Baldwin, J. 1999. "What Determines the Size of Teleost Erythrocytes? Correlations with Oxygen Transport and Nuclear Volume.” Fish. Physiol. Biochem. 20 (1): 31-5.

[28] Feldman, N., Rotter-Maskowitz, A., and Okun, E. 2015. "DAMPs as Mediators of Sterile Inflammation in Aging-Related Pathologies." Ageing Res. Rev. 24: 29-39.

[29] Huang, J., Xie, Y., Sun, X., Zeh, H. J., Kang, R., Lotze, M. T., and Tang, D. 2015. "DAMPs, Ageing and Cancer: The 'DAMP Hypothesis'.” Ageing. Res. Rev. 24: 3-16.

[30] Rebl, A., Goldammer, T., and Seyfert, H. M. 2010. "Toll-Like Receptor Signaling in Bony Fish." Vet. Immunol Immunopathol. 134 (3-4): 139-50.

[31] Castillo-Briceño, P., Bihan, D., Nilges, M., Hamaia, S., Meseguer, J., Garca-Ayala, A., Farndale, R. W., and Muleroa, V. 2011. “A Role for Specific Collagen Motifs during Wound Healing and Inflammatory Response of Fibroblasts in the Teleost Fish Gilthead Seabream.” Mol. Immunol. 48 (6-7): 826-34.

[32] Kiron, V. 2012. "Fish Immune System and Its Nutritional Modulation for Preventive Health Care.” Animal Feed Sci. Tech. 173 (1-2): 111-33.

[33] Tafalla, C., Bogwald, J., and Dalmo, R. A. 2013. "Adjuvants and Immunostimulants in Fish Vaccines: Current Knowledge and Future Perspectives.” Fish and Shellfish Immunology 35 (6): 1740-50.

[34] Vera-Jimenez, N. I., and Nielsen, M. E. 2013. “Carp Head Kidney Leukocytes Display Different Patterns of Oxygen Radical Production after Stimulation with PAMPs and DAMPs.” Molecular Immunology 55 (3-4): 231-6.

[35] Lima, L. C., Ribeiro, L. P., Leite, R. C., and Melo, D. C. 2006. "Stress in Fish.” Revista Brasileira de Reprodução Animal 30 (3/4): 113-7. (in Portuguese)

[36] Tort, L., Balasch, J., and Mackenzie, S. 2003. "Fish Immune System: A Crossroads between Innate and Adaptive Responses.” Imunologia 22 (3): 277-86.

[37] Cle, L.W., Miller, N. W., and Bly, J. E. 1991. "Evolution of Lymphocyte Subpopulations, Their Interactions and Temperature Sensitivities.” In Phylogeny of Immune Functions, edited by Cohen, N., and Warr, G. W. Boca Raton: CRC Press, 191-213. 

Juvenile Piracanjubas (Brycon orbygnianus)

[38] Falcon, D. R., Barros, M. M., Pezzato, L. E., Solarte, W. V. N., and Guimarães, I. G. 2008. "Differential Leucocyte Counts of Nile Tilapia Fed Diets Supplemented Vitamin C and Lipid and Submitted to Low Temperature Stress.” Cien. Anim. Bras. 9: 543-51. (in Portuguese)

[39] Matushima, E. R., and Mariano, M. 1996. "Kinetics of the Inflammatory Reaction Induced by Carrageenin in the Swim Bladder of Oreochromis niloticus (Nile Tilapia).” Brazilian J. Vet. Res. Anim. Sci. 33 (1): 5-10. 